\title{
Heavy hitting: concussions and the courts
}

$\mathrm{F}$ orget Monday Night Football. For former National Football League (NFL) players, the latest game in town appears to be weekly concussion litigation. So prolific have concussion lawsuits become that as of June 14, there were more than 90 filed in American courts, involving nearly 2500 explayers. Experts project the latter tally could easily top 12000 in the months ahead as more and more explayers band together to file concussion claims.

Others project that if the gridironrelated lawsuits are successful, they'll set such a precedent that a flood of similar litigation will be filed on behalf of former National Hockey League players and others who toil in sports in which head blows are common.

It's prompted considerable debate about the legal obligations of sports leagues, associations and administrators, as well as educational institutions, sports equipment manufacturers and others involved in the vast industry of sport, to protect the health and safety of players of any sport at any level of play. Is the introduction of concussion protocols enough? Or can the various sport bodies and institutions be held liable because they failed to introduce laws or regulations to ban hitting, or even such practices as "heading" the ball in soccer?

From that perspective, the outcome of the various NFL lawsuits may be transformative for all sports, as they basically allege that the league breached a common-law duty to "provide players with rules and information to protect the players as much as possible from short-term and long-term health risks." Essentially, they contend that the failure to act or move with measures to improve safety in sports is a form of negligence, for which sport administrators should be held liable.

At the core of the lawsuits lies the proposition that the NFL did not do enough to protect players from the longterm neurocognitive consequences of successive concussions, such as demen-

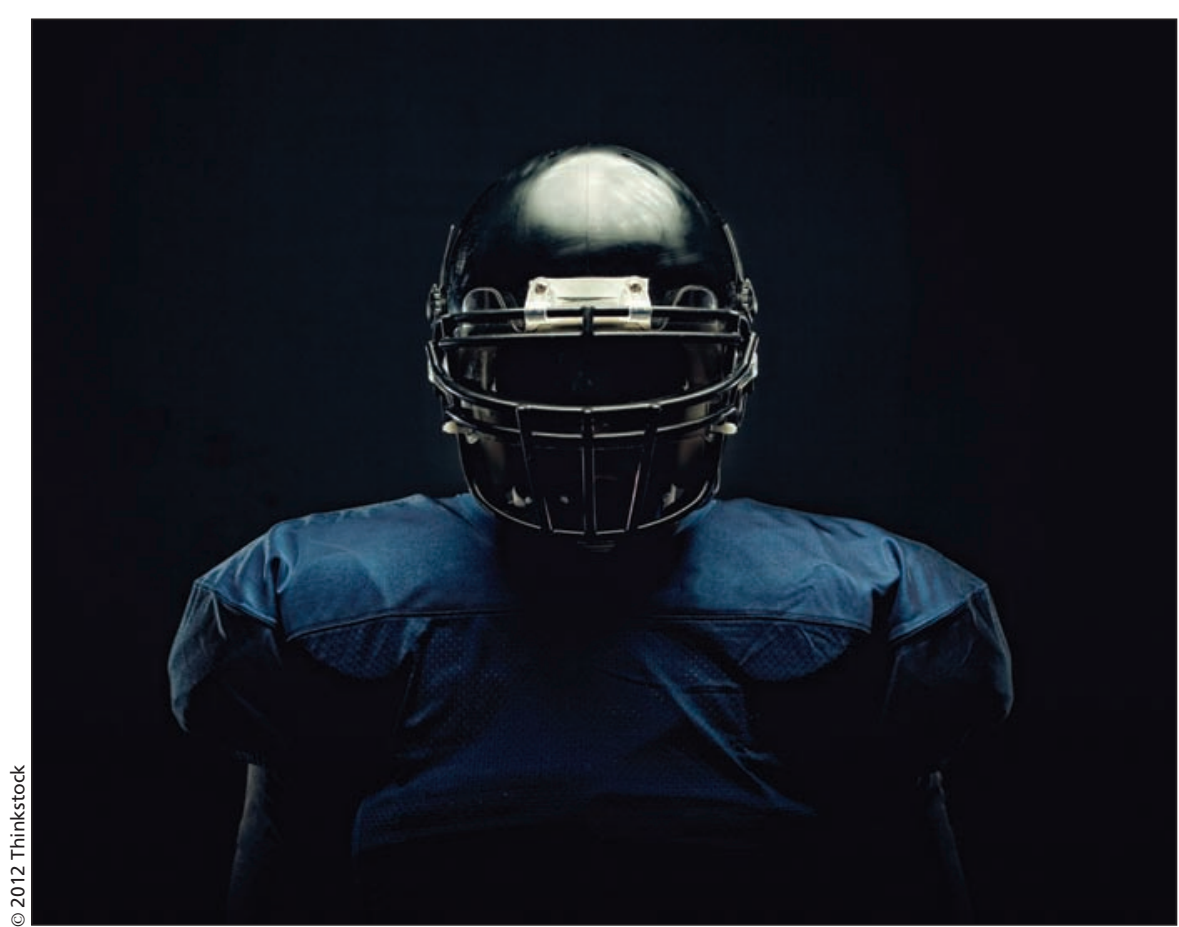

Concussions were once the dark secret of professional football, but now thousands of former players are bringing the problem into the light - and into the courtroom.

tia and memory loss, and that it ignored or denied research linking brain damage to repeated blows to the head.

The NFL counters that the collective bargaining agreement between owners and players, de facto, precludes players from seeking redress for injuries suffered while toiling in the professional ranks.

Dozens of the NFL lawsuits were consolidated in June as a "master complaint," a legal process in the United States that basically allows for suits in different jurisdictions to jointly handle such legal procedures as discovery requests and pretrial motions.

The master complaint, filed in a federal court in Philadelphia, Pennsylvania, alleges that the NFL is guilty of common-law fraud and negligence as it "was aware of the evidence and the risks associated with repetitive traumatic brain injuries virtually at its inception, but deliberately ignored and actively concealed the information from the Plaintiffs and all others who participated in organized football at all levels" (http://nflconcussionlitigation .com/wp-content/uploads/2012/01/NFL -Master-Complaint1.pdf).

"Since its inception, the NFL has recognized, acknowledged and acted in a monopolistic manner, intent on controlling and regulating every aspect of the game of professional football, particularly with respect to player safety and health. The NFL has used this authority to compel all NFL players and participants to follow the policies, rules and regulations the NFL has enacted and imposed," the complaint states.

Although it was aware of the health risks associated with repetitive blows to the head, "the NFL turned a blind eye to the risk and failed to warn and/or impose safety regulations governing this wellrecognized health and safety problem."

The lawsuits essentially hinge on the NFL's decision to create a Mild Traumatic Brain Injury Committee in 1994 to research the effects of concussions and advise the league on measures to prevent and manage such 
injuries, says Paul D. Anderson, webmaster of nflconcussionlitigation.com and a recent graduate of law school.

By establishing a committee with a mandate to investigate the impact of concussions, the league "voluntarily inserted itself into the private and public discussion and research on an issue that goes to the core safety risk for players who participate at every level of the game," and thereby assumed a common-law duty to "use reasonable care" when researching such issues, according to the master complaint.

Instead, the plaintiffs allege, the NFL "engaged in a long-running course of fraudulent and negligent conduct," including a "campaign of disinformation" intended to subjugate research linking successive concussions with later-life cognitive decline. The master complaint also alleges the NFL created "a falsified body of research which the NFL could cite as proof that truthful and accepted neuroscience on the subject was inconclusive and subject to doubt."

The claim of negligence is based on the proposition that the NFL should have been aware of the scientific evidence of the detrimental effects arising from successive head injuries and should have taken appropriate action to protect players, explains Travis Leach, a sports and entertainment attorney at the Jennings, Strouss \& Salmon law firm in Phoenix, Arizona. The claim of fraud is based on the proposition that the NFL was aware of the potential effects, but disregarded them, he adds.

In response to the master complaint, the NFL argued that neither claim is justified. "Any allegation that the NFL has sought to mislead players has no merit. It stands in contrast to the league's many actions to protect players and advance the science and medical understanding of the management and treatment of concussions," NFL spokesman Brian McCarthy said in a statement (www.nfl .com/news/story/09000d5d829a3959 /article/master-complaint-says-nfl-hid -brain-injury-links).

The master complaint also alleges that Riddell Sports Inc., which makes the "official helmet of the NFL," was equally negligent. "Despite years of science and medicine linking the risk of long-term brain injury from repeat concussions, it was not until the release of the Revolution Helmet [in 2002] wherein a notification reminding players to 'sit out' if they suffer a concussion was placed on the Revolution helmet," it states.

The NFL's defense is based on the argument that issues of health and safety fall within the purview of the collective bargaining agreement between the league and the players, not the courts, Leach says. The former players counter that the matter should be subject to legal remedies on the grounds that the NFL was bargaining in bad faith by withholding information about the health impacts of concussions from the players and lawyers negotiating those contracts, he adds.

The spate of concussion lawsuits isn't confined to the NFL. A suit against the National Collegiate Athletic Association alleges that it was similarly negligent in protecting athletes. The association "failed to address and/or correct the coaching of tackling methodologies that cause head injuries; the NCAA has failed to implement system-wide 'return to play' guidelines for student-athletes who have sustained concussions; the NCAA has failed to implement systemwide guidelines for the screening and detection of head injuries; the NCAA has failed to implement legislation addressing the treatment and eligibility of student-athletes who have sustained multiple concussions during play; and the NCAA has failed to implement a support system for student-athletes who, after sustaining concussions, are left unable to either play football or even lead a normal life," the suit alleges (www.cmaj.ca/lookup/doi/10.1503/cmaj .109-4070). — Michael Monette, CMAJ

CMAJ 2012. DOI:10.1503/cmaj.109-4243

Editor's note: First of a two-part series.

Next: Heavy hitting: concussions and safety law 